\title{
PATOLOGIA EM CONCRETO ARMADO E SEUS MÉTODOS DE RECUPERAÇÃO ESTRUTURAL
}

\author{
Joaquim Júlio Almeida Júnior \\ Thales Sousa Fraga \\ Beatriz Campos Miranda \\ Victor Júlio Almeida Silva
}

\begin{abstract}
Universidade Estadual Paulista (UNESP)
Centro Universitário de Mineiros (UNIFIMES)

Centro Universitário de Mineiros (UNIFIMES)

Faculdade Almeida Rodrigues (FAR)
\end{abstract}

\begin{abstract}
Resumo: As construções tratam-se de elementos absolutamente essenciais em grande parte das atividades da conjuntura social e mercadológica no mundo, tanto no ambiente comercial e industrial, quanto para fins residenciais. No Brasil, o segmento relacionado a construção civil exerce importante responsabilidade no processo de evolução mercadológica, social e econômica, destacando-se como protagonista na promoção de recursos financeiros, abertura de vagas no mercado de trabalho, investimentos em diversas áreas e aumento da qualidade de vida dos indivíduos. Por meio do crescimento mercadológico na área da construção civil, as organizações desse segmento tiveram diversos desafios em relação a gastos excessivos devido ao uso inapropriado de materiais, além de baixo nível de produção, aumento sobre custos na obra e ausência de profissionais qualificados para atender as necessidades e demandas dos projetos relacionados a engenharia civil. Com foco nos aspectos comportamentais, sociais e econômicos do público-alvo, as construções precisam atender as demandas e necessidades dos consumidores, com a finalidade de atender tais anseios. As construções baseadas em concreto armado encontram-se como a técnica de construção mais usada em território brasileiro e, nesse sentido, também apresentam uma grande quantidade de patologias, as quais costumam acontecer em várias fases do processo construtivo de uma obra. É necessário, dessa maneira, realizar uma análise adequada sobre as principais causas, bem como agentes causadores, além de planejar métodos preventivos e corretivos. As patologias em concreto armado têm a capacidade de gerar prejuízos materiais, financeiros e, inclusive, vitais - em caso de vítimas diante de graves problemas na construção - para consumidores, gestores, profissionais de engenharia civil e demais indivíduos envolvidos com a obra. A fim de avaliar os problemas envolvendo o concreto armado na área da construção civil, ressalta-se a patologia em concreto armado. Averiguando-se essa conjuntura, ressalta-se o seguinte problema de pesquisa: quais são os principais métodos de recuperação estrutural em relação às patologias que ocorrem em concreto armado? Como hipótese, defende-se que os problemas que potencialmente atingem as estruturas são diversos e numerosos, e poderiam ser evitados pela adoção de cuidados mais rigorosos na confecção de projetos, na especificação e escolha dos materiais utilizados, no uso responsável da estrutura e de sua manutenção preventiva, tais cuidados poderiam, facilmente, reduzir, atenuar ou até extinguir a necessidade de sistemas de recuperação ou reparos de estruturas ameaçadas. O objetivo geral é averiguar as principais características sobre patologia em concreto armado. Sobre a definição dos objetivos específicos, estabeleceu-se o seguinte: verificar aspectos conceituais sobre patologia em concreto armado; investigar questões relevantes sobre a natureza do agravamento estrutural em concreto armado; analisar métodos de recuperação estrutural no concreto armado. A metodologia adotada nesse estudo foi a seguinte: Revisão Bibliográfica Narrativa (Revisão de Literatura).
\end{abstract}

Palavras-chave: Concreto Armado. Construção Civil. Engenharia Civil. Métodos de Recuperação Estrutural. Patologia em Concreto Armado.

\section{PATHOLOGY IN ARMED CONCRETE AND ITS METHODS OF STRUCTURAL RECOVERY}

Abstract: The constructions are absolutely essential elements in most of the activities of the social and market conjuncture in the world, both in the commercial and industrial environment, as well as for residential purposes. In Brazil, the segment related

\author{
Fonte de financiamento: Nenhum \\ Conflito de interesse: Os autores declaram não haver nenhum conflito de interesse. \\ E-mail do autor-correspondência: joaquimjuliojr@gmail.com \\ Data de recebido: 20/12/2020 \\ Data de aprovado: 12/01/2021 \\ Editora: Elisângela Maura Catarino.
}


to civil construction exercises an important responsibility in the process of market, social and economic evolution, standing out as a protagonist in the promotion of financial resources, opening vacancies in the labor market, investments in several areas and increasing the quality of individuals' lives. Through market growth in the civil construction area, organizations in this segment faced several challenges in relation to excessive spending due to inappropriate use of materials, in addition to low production levels, increased costs on the construction site and the absence of qualified professionals to meet needs and demands of projects related to civil engineering. With a focus on the behavioral, social and economic aspects of the target audience, the buildings need to meet the demands and needs of consumers, in order to meet such desires. Constructions based on reinforced concrete are the most used construction technique in Brazilian territory and, in this sense, they also present a large number of pathologies, which usually happen in several phases of the construction process of a work. It is necessary, therefore, to carry out an adequate analysis of the main causes, as well as causative agents, in addition to planning preventive and corrective methods. Reinforced concrete pathologies have the capacity to generate material, financial and even vital losses - in the event of victims facing serious construction problems - for consumers, managers, civil engineering professionals and other individuals involved with the work. In order to evaluate the problems involving reinforced concrete in the area of civil construction, the pathology in reinforced concrete is highlighted. When investigating this situation, the following research problem is highlighted: what are the main methods of structural recovery in relation to the pathologies that occur in reinforced concrete? As hypothesized, it is argued that the problems that potentially affect the structures are diverse and numerous, and could be avoided by adopting more rigorous care in the design of projects, in the specification and choice of materials used, in the responsible use of the structure and of its preventive maintenance, such care could easily reduce, mitigate or even extinguish the need for recovery systems or repairs to endangered structures. The general objective is to investigate the main characteristics of reinforced concrete pathology. Regarding the definition of specific objectives, the following was established: to verify conceptual aspects about reinforced concrete pathology; investigate relevant questions about the nature of the structural deterioration in reinforced concrete; analyze structural recovery methods in reinforced concrete. The methodology adopted in this study was as follows: Narrative Bibliographic Review (Literature Review).

Key words: Armed Concrete. Armed Concrete Pathology. Civil Construction. Civil Engineering. Structural Recovery Methods.

Como citar o artigo: JÚNIOR, Joaquim Júlio Almeida. FRAGA, Thales Sousa. MIRANDA, Beatriz Campos. SILVA, Victor Júlio Almeida. Patologia em concreto armado e seus métodos de recuperação estrutural. Revista Científica Novas Configurações-Diálogos Plurais, v. 2 n. 1,2021

\section{INTRODUÇÃO}

A construção civil teve seu ritmo de desenvolvimento aumentado em virtude da demanda, cada vez maior, por edificações, para fins laborais, industriais ou habitacionais, junto da respectiva modernização da sociedade como um todo, o que levou a um evidente avanço científico e tecnológico (HERANI, 2004). Em consequência do crescimento acelerado da construção, diversas estruturas mostraram-se insatisfatórias quanto a seu desempenho, por apresentarem falhas involuntárias, imperícias, utilização inadequada dos materiais escolhidos, desgaste natural ou descuidos no planejamento, por fim existem vários fatores que colaboram com a deterioração das estruturas.

A patologia estrutural refere-se à área de engenharia civil que trata do estudo das causas, manifestações, implicações e mecanismos de manifestações de falhas e dos métodos de desgaste das estruturas. As patologias em construções são os problemas mais importantes do comprometimento e da vida útil das edificações. Gonçalves (2015) destaca o concreto como um dos materiais mais utilizados nos projetos de estruturas de concreto, que, por sua vez, por meio do projeto e execução, delimitarão o potencial aparecimento de patologias, bem como da intensidade das mesmas.

A execução de estudos se faz essencial na busca da avaliação, caracterização e diagnóstico de possíveis danos nas construções, já que são fundamentais para o decurso de geração e uso das construções; possibilitam compreender ações eficazes e capazes de reduzir a ocorrência de anomalias e falhas, o que faz com que a qualidade geral das edificações melhore e otimiza a administração dos recursos (MIOTTO, 2010). Uma nova área do conhecimento, que visa o estudo das manifestações patológicas possíveis de ocorrer no concreto armado é conhecida como patologia em concreto armado.

De acordo com Souza e Ripper (1998) a designação genérica de patologia das estruturas faz com que este novo campo da engenharia das construções trate dos princípios, modelos de manifestação, consequências e métodos de ocorrência dos danos e mecanismos envolvidos na degradação das estruturas. Segundo Trindade (2015) os motivos que ocasionam danos e avarias em estruturas são vários e diversos, assim, se faz essencial o estudo do ramo da engenharia que trata de tais situações, para que possam ser evitadas as ocorrências patológicas que reduzem a longevidade das 
estruturas, bem como a necessidade da compreensão de formas de solucionar e restabelecer as estruturas que degradaram, de forma a recuperá-las e impedir que o fator causal continue a causar a mesma falha.

No Brasil, se faz obrigatória a garantia de cinco anos para construções, dada pelos respectivos construtores, cujo prazo é estabelecido por meio do Código Civil (BRASIL, 2002) - Lei $n^{\circ} 10.406$. No entanto, a pesquisa para que patologias sejam minimizadas durante este intervalo de cinco anos permanece escassa. Uma explicação para tal fato é que uma parcela importante do aprendizado no âmbito da engenharia estrutural é dirigida para o projeto e a execução das edificações, refutando a recuperação e a manutenção das estruturas usuais. A escassez de manutenção resulta na ocorrência de pequenos sintomas patológicos, estes com um reduzido custo de restauração, que progridem para situações de comportamento insatisfatório em ambientes insalubres, com aspectos estéticos ineficientes, com a possibilidade de insegurança estrutural, e por fim de elevado custo de recuperação (GONÇALVES, 2015).

Averiguando-se essa conjuntura, ressalta-se o seguinte problema de pesquisa: quais são os principais métodos de recuperação estrutural em relação às patologias que ocorrem em concreto armado? Como hipótese, defende-se que os problemas que potencialmente atingem as estruturas são diversos e numerosos, e poderiam ser evitados pela adoção de cuidados mais rigorosos na confecção de projetos, na especificação e escolha dos materiais utilizados, no uso responsável da estrutura e de sua manutenção preventiva, tais cuidados poderiam, facilmente, reduzir, atenuar ou até extinguir a necessidade de sistemas de recuperação ou reparos de estruturas ameaçadas. O objetivo geral é averiguar as principais características sobre patologia em concreto armado. Sobre a definição dos objetivos específicos, estabeleceuse o seguinte: verificar aspectos conceituais sobre patologia em concreto armado; investigar questões relevantes sobre a natureza do agravamento estrutural em concreto armado; analisar métodos de recuperação estrutural no concreto armado.

Dentre as principais citações indicadas, destacam-se os autores a seguir: Azevedo (2011); Botelho e Marchetti (2004); Cánovas (1988); Gonçalves (2015); Herani (2004); Miotto (2010); Neville e Brooks (2013); Relvas (2004); Souza (2006); Trindade (2015). A metodologia adotada nesse estudo foi a seguinte: Revisão Bibliográfica Narrativa (Revisão de Literatura). Em relação a estrutura, destacam-se os seguintes elementos: capítulo 1 - introdução; capítulo 2 - foram verificados aspectos conceituais sobre patologia em concreto armado; capítulo 3 - foram investigadas questões relevantes sobre a natureza do agravamento estrutural em concreto armado; capítulo 4 - foram analisados métodos de recuperação estrutural no concreto armado; capítulo 5 - metodologia; considerações finais.

\section{PATOLOGIA EM CONCRETO ARMADO: ASPECTOS CONCEITUAIS}

$\mathrm{Na}$ antiguidade, a pedra natural era bastante utilizada na construção de projetos, fortificações e para a transposição de espaços sobre rios ou depressões de solo. A estrutura como um elemento que suporta a compressão é considerada um excelente material, porém ineficaz à tração, podendo ser rompida em casos de espaços maiores. Em função desta situação, os romanos iniciaram a construção de vãos na forma de arco, de forma a evitar rupturas.

De acordo com Botelho e Marchetti (2004), os romanos se mostraram inovadores na construção de pontes de pedra em formato de arco - Figura 1. No caso de não ser possível a utilização de vigas retas para transpor vãos maiores, os romanos adotaram uma estratégia: o uso de arcos em locais onde cada uma das peças de pedra era confeccionada de forma a trabalhar apenas sob compressão.

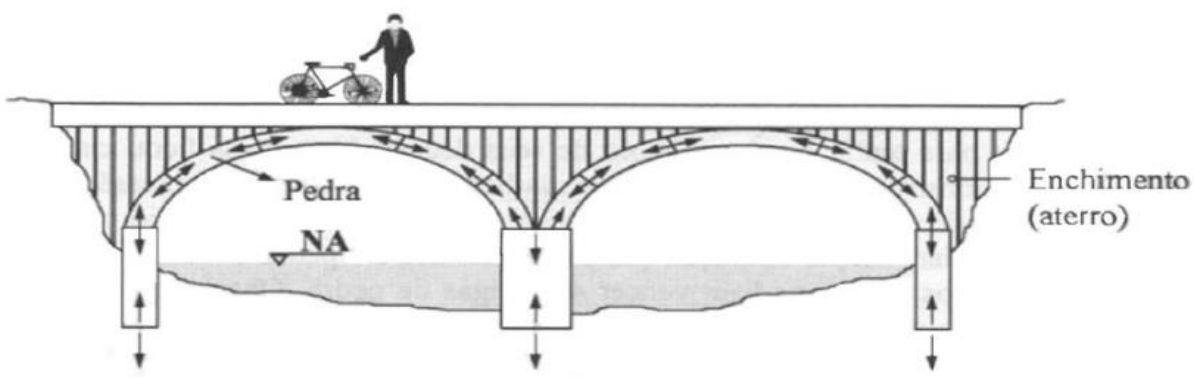

Figura 1 - Arcos requisitados por meio de compressão. Fonte: Botelho e Marchetti (2004). 
Em grandes vãos era necessária a utilização de arcos múltiplos, o que implicava em uma execução mais difícil, graças à tecnologia limitada da época. Apesar da descoberta e utilização do concreto, elemento resultante da fusão de cimento, pedra, areia e água, as adversidades permaneceram, já que o material é resistente à compressão numa ordem dez vezes maior que à tração. Nessa perspectiva, a zona tracionada é suscetível à ocorrência de fissuras que podem ser desde um simples afeamento estético até mesmo condenar toda a estrutura ao colapso, de acordo com as dimensões da mesma.

Em virtude desta situação, surgiu a possibilidade de união dos dois materiais, de forma que as necessidades de resistência à compressão e à tração pudessem ser atendidas. Dessa forma, passa-se a ter uma região solicitada somente pela tração, outra zona sobre a qual age somente a compressão, e uma terceira, considerada como uma linha neutra (Figura 2), onde não há compressão ou tração (BOTELHO; MARCHETTI, 2004).

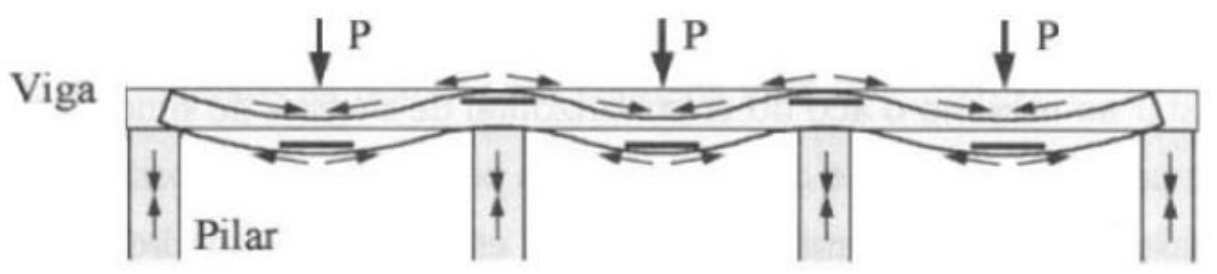

Figura 2 - Regiões de tração e compressão. Fonte: Botelho e Marchetti (2004).

Para resolver a questão da baixa resistência à tração, são adicionadas barras de aço no segmento da seção onde a tração ocorre, e o concreto permanece como encarregado pelo suporte da compressão (Figura 3).
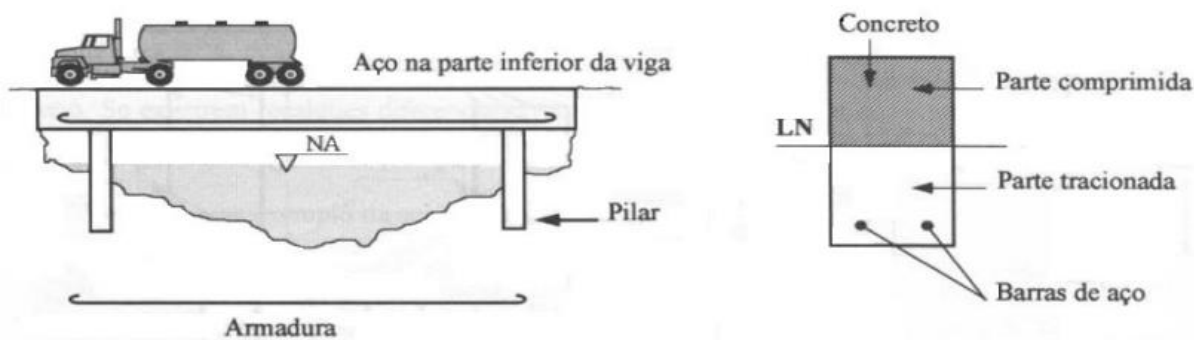

Figura 3 - Regiões de tração, compressão e linha neutra em relação à estrutura Fonte: Botelho e Marchetti (2004).

Assim, o concreto armado se consolidou como um método que atende às demandas da época. A partir da descoberta e utilização do concreto armado, bem como dos benefícios trazidos por este quando comparado às demais técnicas e materiais da época, desencadeou-se uma progressiva e crescente utilização deste material. Juntamente com a utilização do concreto armado, vieram as manifestações patológicas que este está sujeito, tanto pelo descuido e má utilização como pela mão-de-obra não qualificada em edificações ou mesmo a ignorância no emprego correto deste material (TRINDADE, 2015).

Nos países onde a economia é crescente, houve uma evidente aceleração em vários domínios da engenharia, principalmente na área da construção civil, onde as habitações são erguidas com dimensões cada vez maiores e de maneira cada vez mais ágil.

A partir do momento em que a construção se inicia, esta já é suscetível ao surgimento de falhas de natureza diversa, relacionadas a causas distintas, como por exemplo, a falta de mão-de-obra qualificada, a ausência do controle de qualidade, a execução da obra em condições de baixa qualidade, as condições de trabalho inadequadas aos funcionários, a utilização de materiais de qualidade insuficiente ou questionável, a não compreensão da necessidade da 
responsabilidade técnica e em casos mais raros a sabotagem. Takata (2009) cita exemplos de patologias causadas por falhas na execução de estruturas de concreto armado, como as fissuras de vigas causadas pela ausência de barras de aço, as fraturas de elementos estruturais ocasionadas pelo escoramento inadequado das formas e as falhas no concreto causadas pela vibração do concreto.

Após a finalização das fases de concepção e execução estrutural, mesmo que o sucesso almejado tenha sido atingido até o momento, sem falhas ou com ínfimas margens para a ocorrência de danos patológicos, ainda é possível a ocorrência de patologias pelo manuseio inadequado.

Trindade (2015) ressalta a possibilidade de danos estruturais devido ao descuido ou desconhecimento, posteriores à entrega da obra ao usuário. O uso de uma estrutura deveria ser considerado como qualquer outro equipamento, seja mecânico ou elétrico, isto é, o uso deve ser pautado pelo respeito ao projeto e todas as manutenções indicadas pelos responsáveis técnicos realizadas de forma adequada. No que tange ao uso do concreto, especial atenção deve ser dispensada aos produtos que possam causar a corrosão deste e das armaduras de aço, bem como o respeito aos valores de sobrecarga suportados pelos elementos estruturais (Figura 4).

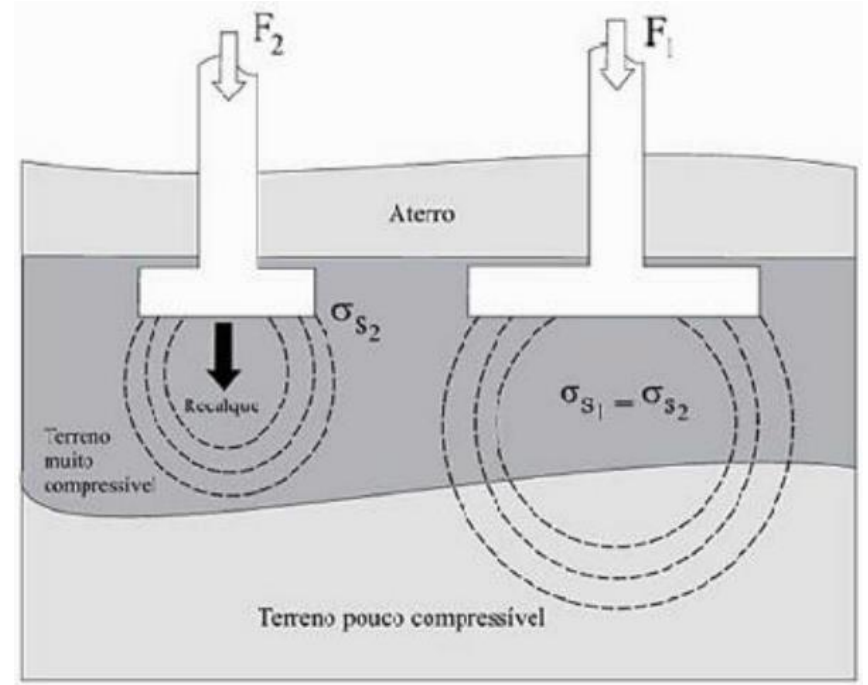

Figura 4 - Bulbo de tensões em terreno pouco compressível.

Fonte: Souza e Ripper (1998).

Algumas das patologias possíveis nesta etapa são as fissuras pela retirada de alguma estrutura essencial para a abertura de vãos, como é o caso de janelas, portas ou espaços destinados a outras finalidades (SOUZA; RIPPER, 1998).

\section{NATUREZA DO AGRAVAMENTO ESTRUTURAL EM CONCRETO ARMADO}

Os agentes causais das manifestações patológicas podem ser de origens distintas, desde um erro humano no projeto ou na sua execução, até dificuldades com a estrutura química de componentes de materiais específicos, ou mesmo pela ação de agentes agressores do concreto ou armaduras.

Souza e Ripper (1998) destacam que as causas consideradas intrínsecas podem ser definidas como as causas nas quais os processos de degradação das estruturas são inerentes a estes, isto é, causas advindas dos próprios materiais e suas peças estruturais, ocorridas durante o período de execução ou de utilização, ou por erro humano, ou por questões próprias ao material concreto, e até mesmo pela ação externa, como acidentes.

Em relação às falhas cometidas pelos profissionais encarregados pela construção, destaca-se o fato de que os erros construtivos e os erros de concepção de projeto podem ser causados por falha humana na grande maioria dos casos, principalmente pela qualidade questionável da mão-de-obra contratada. Algumas das falhas humanas mais comuns como causas de patologias em edificações são as falhas de execução, as concretagens ineficientes, o uso de 


\section{PATOLOGIA EM CONCRETO ARMADO E SEUS MÉTODOS DE RECUPERAÇÃO ESTRUTURAL}

escoramentos e formas inadequadas, a utilização de armaduras insuficientes, a utilização errônea de materiais de construção e a não observância do controle de qualidade.

$\mathrm{Na}$ avaliação das deficiências de concretagem, é importante considerar diversos fatores que podem influenciar o sucesso da construção, tais como o transporte, o lançamento, as juntas de concretagem, o adensamento (Figura 5) e o tempo de cura necessário, todos estes fatores poderão influenciar o resultado esperado e o tempo de execução da obra.

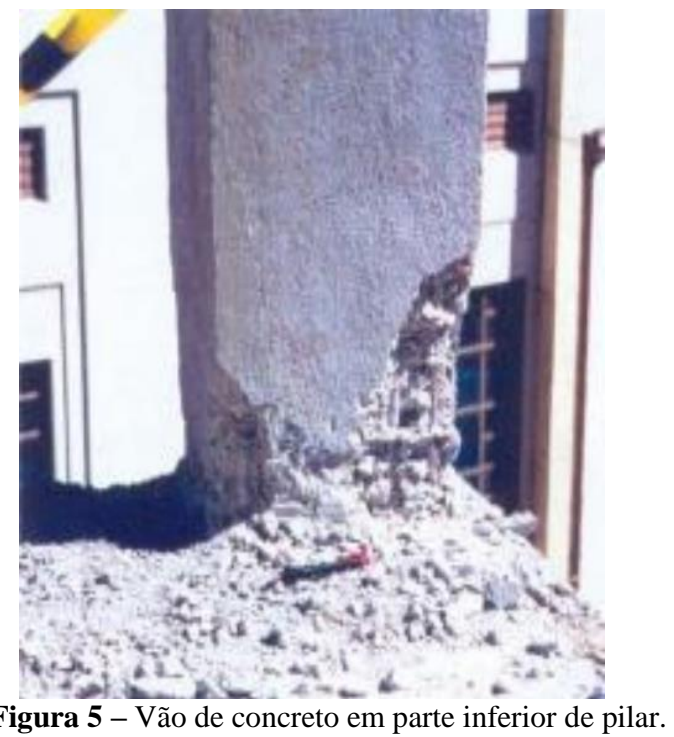

Figura 5 - Vão de concreto em parte inferior de pilar. Fonte: Figuerola (2006)

Em relação ao transporte do concreto realizado na obra ou por concreteiras, do momento da saída, ou por meio de carrinhos de mão ou por caminhões, até o último instante de aplicação, deverá ser realizado de forma a não permitir a massa secar, e por isso perder a fluidez, tal descuido acarretaria na redução do tempo de trabalhabilidade deste. O cronograma de execução também deve levar em consideração o tempo necessário para a concretagem da primeira camada e o tempo gasto no transporte da segunda camada, de modo a que o intervalo entre estas não seja exagerado e por isso gere juntas não desejadas e superfícies com aderência reduzida.

Quanto ao lançamento do concreto, este deve ser realizado de forma delicada, a fim de evitar o deslocamento das armaduras de aço, assim como deve ser lançado no local mais próximo possível de seu destino final, a fim de evitar a distribuição deste.

Isaia (1988) destaca que o funcionário responsável pela concretagem deve ser considerado como essencial à obra, e este profissional deve ter ciência de sua responsabilidade, ter uma noção intuitiva do volume preenchido por cada porção de concreto lançado. Para a concretagem de colunas, a altura em queda livre não deverá ultrapassar a medida de dois metros, a fim de evitar a segregação dos componentes da mistura.

Um outro fator que pode ser responsável por manifestações patológicas é o adensamento, tal processo tem a função de retirar ou diminuir ao máximo os espaços vazios no concreto, de forma a permitir que este tenha uma maior resistência mecânica e possibilite um melhor acomodamento do concreto nas formas e entre as armaduras presentes (NEVILLE; BROOKS, 2013).

Nesse sentido, visando um resultado altamente eficiente, Neville e Brooks (2013) colocam como destaque os seguintes pré-requisitos: evitar ao máximo o arrastamento do concreto; lançar o concreto de maneira uniforme, distribuindo as camadas com tamanhos semelhantes, evitando o lançamento deste em pilhas ou montes altos; a espessura das camadas lançadas deverá ser condizente ao equipamento utilizado para o adensamento; e depois do lançamento de uma camada de concreto, esta camada deverá ser adensada anteriormente à próxima camada, esta ação permitirá que o ar aprisionado na pasta de concreto seja retirado, garantindo assim maior eficiência do processo. 
A interrupção do lançamento do concreto, devido ao tempo de transporte, que abastece o local concretado por partes, causa, de forma inevitável, as juntas de concretagem. É aconselhável que tais juntas não estejam localizadas em regiões que sofrem demasiadas tensões tangenciais, bem como em locais com possibilidade de deslizamentos de uma face à outra (Figura 6).

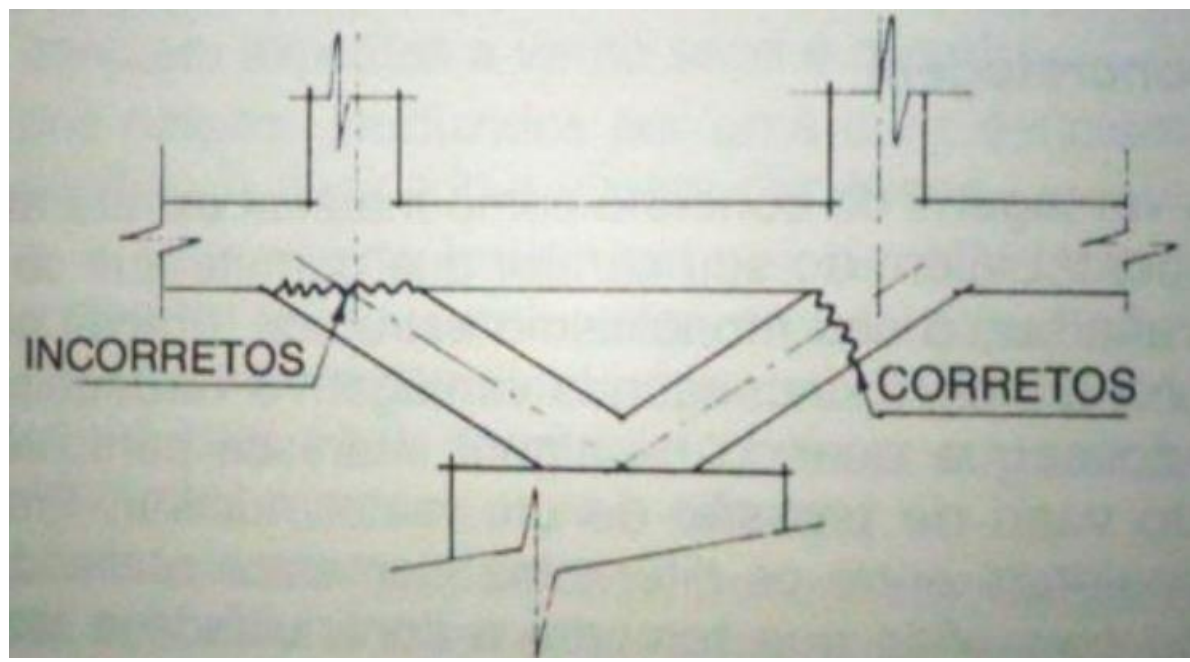

Figura 6 - Exemplos de realização adequada e equivocada referente às juntas de concretagem. Fonte: Thomaz (1989).

Isaia (1988) indicou uma sequência de medidas importantes para evitar ou diminuir os danos causados durante a execução da junta, dentre eles destacam-se: a região onde a concretagem será interrompida, até o ponto do próximo concreto ter seu volume lançado, deverá ser avaliada com antecedência de forma que seja possível a identificação das regiões de baixa solicitação, principalmente ao cisalhamento; utilizar barras de aço no concreto antigo, para proporcionar o alívio dos esforços no plano da junta; a nata superficial do concreto antigo deverá ser retirada por meio do apicoamento, a fim de que esta torne-se menos lisa, o que proporciona uma melhor aderência desta camada em relação à próxima camada a ser lançada; os locais de maior solicitação da junta, ou seja, os pontos de contato entre as camadas subjacentes, serão os mais sensíveis à passagem de água ou outro fluido presente no local, neste caso indicase a utilização de um adesivo estrutural na face da camada em contato com o concreto recém adicionado, de forma a elevar a estanqueidade e a impermeabilidade.

De acordo com Trindade (2015), a cura do concreto permanece como um processo merecedor de especial atenção. Tal processo pode ser realizado de diversas formas como a molhagem de formas no caso de colunas, a irrigação das superfícies, a cobertura das superfícies com materiais que permitam a manutenção da umidade desejada, o uso de películas de cura a vapor, entre outros.

Embora o procedimento da cura do concreto não seja, por diversas ocasiões, considerado importante, bem como os cuidados envolvidos, principalmente nas obras classificadas como de pequeno ou médio porte, existe um agravamento associado a este problema nos casos de a execução ser conduzida por empreiteiros com pouco conhecimento técnico. Erros também podem ser cometidos por profissionais atuantes há tempos no mercado, e por isso acreditarem que já conhecem tudo que pode estar envolvido com o processo, de forma a não renovar ou aprimorar as técnicas adotadas, sob a alegação de que suas edificações nunca sofreram danos. Porém, geralmente é desconsiderado ou desconhecido o saber científico, onde a cura do concreto é devida a uma reação química entre a água e o cimento (MARCELLI, 2007).

Outro fator, por muitas vezes desconsiderado, é a limpeza antes da concretagem, bem como a revisão das formas, para identificar se alguma destas se encontra com a estanqueidade insuficiente, evitando a fuga da nata do cimento, o que permitirá os agregados serem expostos. 
Takata (2009) ressalta a utilização de formas para delimitar o concreto e as barras de aço, tal utilização deverá ser realizada no local mais próximo possível da indicada no projeto, bem como respeitar todas as medidas indicadas, incluindo o uso de nível e prumo dos elementos estruturais. A montagem das formas deverá ser conduzida corretamente, a fim de permitir o travamento necessário no instante, ou logo após, o recebimento do concreto, é importante que as formas suportem o peso do concreto, e assim não mudem de formato pela ação do peso, caso contrário é possível que mudanças pequenas ocorridas na geometria ou mesmo em aberturas de vigas, colunas, lajes ou qualquer outro elemento estrutural, originem problemas patológicos, aumentando, de sobremaneira, o custo da obra.

Mesmo atentando para a segurança da estrutura, é importante verificar o projeto e a execução das formas de forma correta. Tal necessidade se dá pelas dificuldades de que, quando formas e escoramentos são incorretamente planejados ou executados (Figura 7), terminam por afetar a os custos financeiros envolvidos, somando valores adicionais ao orçamento final, o que acarreta prejuízos, já que normalmente estão envolvidos serviços adicionais necessários para a correção dos danos, comprometendo a esfera da estética (MARCELLI, 2007).

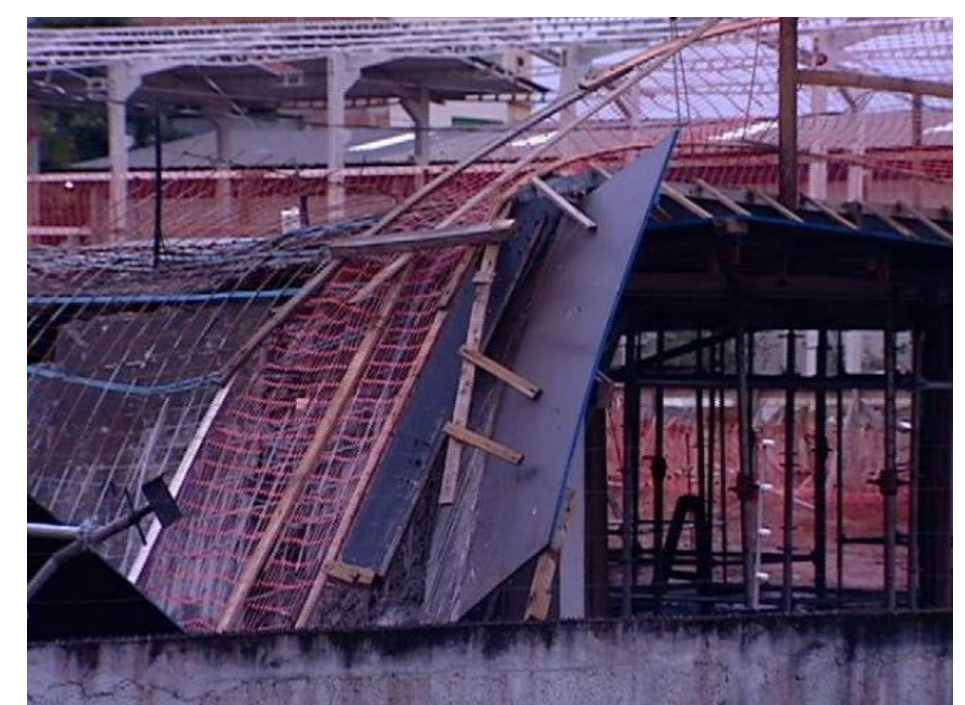

Figura 7 - Problema com laje causado por falhas no planejamento e/ou na execução do escoramento. Fonte: Trindade (2015).

Embora o sucesso da concretagem seja alcançado, e mesmo algum tempo após este ter ocorrido, permanecem ainda alguns cuidados que devem ser considerados a fim de evitar danos estruturais. O período entre a desforma e a retirada de escoramento deverá ser seguido, este tempo é calculado considerando diversos fatores, como o tipo de cimento escolhido, o tipo de cura adotado e o cálculo estrutural. A forma de remoção dos escoramentos também deve ser considerada, um exemplo é o caso de balanços, o elemento estrutural deverá ter suas escoras retiradas da extremidade do balanço na direção do engaste, por certo a não observância levará à ocorrência de trincas na estrutura. O balanço, assim como outros, decorre do agente causador de danos no concreto armado, ou seja, da deficiência das formas e escoramentos (TRINDADE, 2015).

Nas construções que utilizam concreto armado, é comum a ocorrência de falhas na ordenação das barras de aço, tal erro decorre de uma interpretação errônea dos projetos desenvolvidos, causando a organização invertida da posição das barras de aço em um elemento estrutural específico. Uma ferragem insuficiente pode ser decorrente do projeto diretamente, o que eliminaria a responsabilidade pela execução da culpa pela ausência de quantidade adequada ou ordenamento correto do aço, neste caso especifico, a culpabilidade seria dirigida ao responsável técnico, que realizou o cálculo das armaduras ou cometeu falhas na transmissão para a planta da quantidade, do detalhamento e das medidas de ferragem necessárias (NEVILLE; BROOKS, 2013).

Embora um projeto estrutural possa ter sido concebido e executado de forma correta, obedecendo as normas especificadas pela Associação Brasileira de Normas Técnicas (ABNT), bem como tenha sido interpretado pelos 
PATOLOGIA EM CONCRETO ARMADO E SEUS MÉTODOS DE RECUPERAÇÃO ESTRUTURAL

profissionais envolvidos de forma correta, mesmo assim é possível apresentar problemas, como por exemplo pela localização das armaduras ter sido modificada durante a concretagem. Esta modificação de posicionamento é um problema comum em lajes, onde as barras de aço são desalinhadas de sua posição original devido ao trânsito de funcionários, uso de utensílios como o carrinho de mão ou outros, tais movimentos modificam as dimensões e as posições primeiras da ferragem (GONÇALVES, 2015).

De acordo com Botelho e Marchetti (2004), o cobrimento sobre as armaduras é um dos fatores causadores de deterioração de materiais, caso não seja considerado e executado. Os valores do cobrimento devem seguir, rigorosamente, o preceituado pela $\mathrm{ABNT}$, de outro modo poderia, até mesmo, facilitar o aparecimento e progressão da corrosão de armaduras; neste caso, é essencial a utilização de espaçadores. O valor da ancoragem deve, da mesma forma, seguir o estabelecido na norma dita, pois, uma extensão abaixo da necessária poderia, facilmente, facilitar a ocorrência de trincas no material.

Takata (2009) destaca que determinados materiais, quando manuseados de forma inadequada ou fora de sua especificação, poderiam ocasionar diversos danos para uma construção, o que traz consigo uma série de prejuízos financeiros, com destaque para o aço e os aditivos. Em relação ao aço, este material é usado em formato de faixas entre os elementos estruturais, seu uso poderá ser a causa de danos, desde pequenas trincas até o colapso total de uma estrutura onde os mesmos não esteja em quantidades adequadas ao uso, ou até mesmo quando utilizado em quantidades adequadas mas em bitolas menores daquelas previstas no projeto da obra, ou ainda quando as barras são posicionadas incorretamente na estrutura. No que tange aos materiais que podem originar desgaste no concreto, devem-se ser citados os aditivos, em uma posição de importância, uma vez que estas substâncias são capazes de modificar as propriedades do concreto, seu uso está baseado na redução dos pontos fracos, no aumento da qualidade deste, e na redução dos custos da obra. Com efeito, quando utilizados de maneira inadequada, poderão levar o concreto a ter sua resistência e durabilidade alteradas a ponto de sofrer colapso. O emprego de agregados reativos pode produzir reações expansivas com o cimento, de forma a criar fissuras na estrutura e, assim, reduzir a resistência mecânica da mesma (Figura 8).

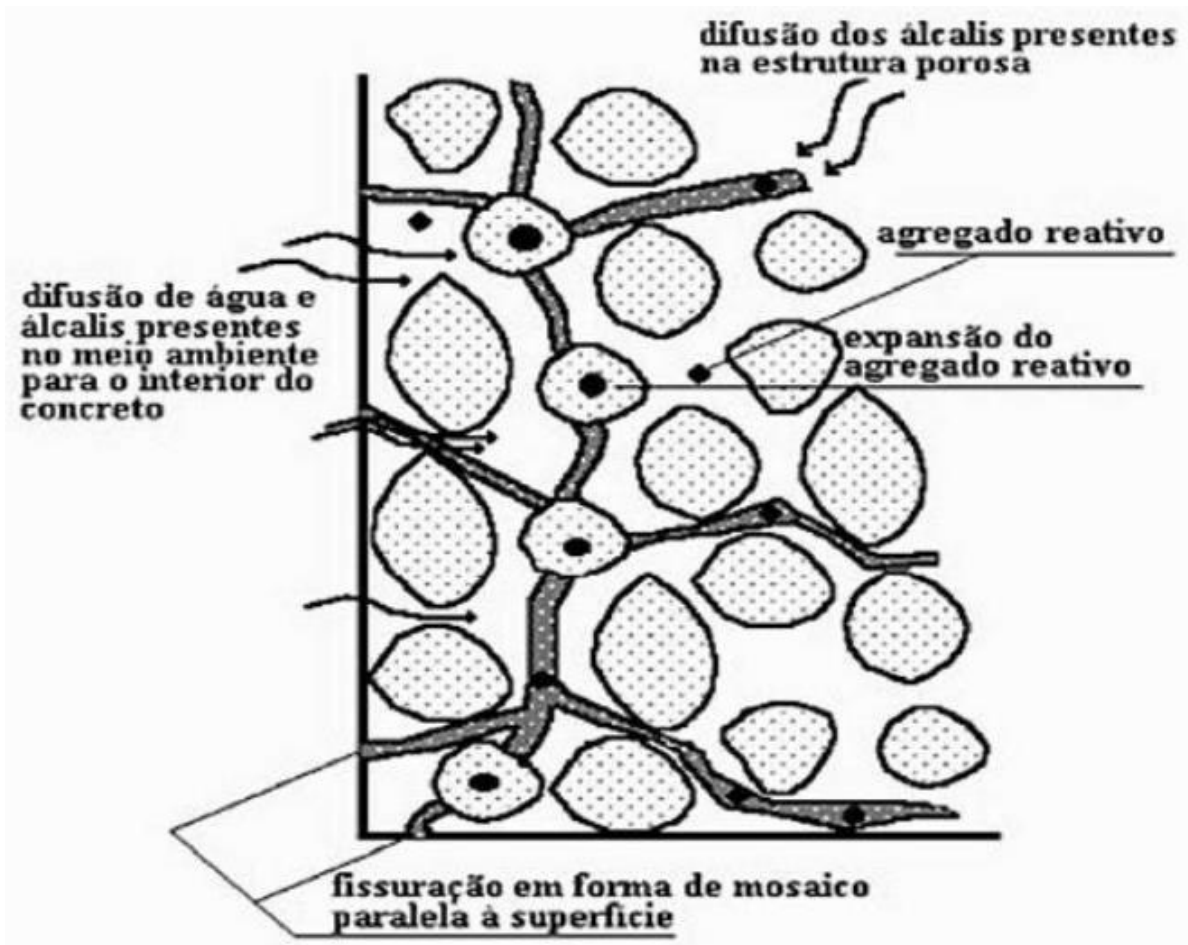

Figura 8 - Realização do reativo álcalis-agregado em relação ao concreto. Fonte: Souza e Ripper (1998).

Segundo Thomaz (1989), um controle de qualidade ineficiente para estruturas de concreto armado é um dos fatores mais relevantes para a ocorrência de patologias. $\mathrm{O}$ aço e o concreto são os materiais que respondem pela 
durabilidade e resistência dos elementos estruturais, e justamente por isso necessitam de um padrão de qualidade bastante restrito, desde a produção até a execução de uma determinada estrutura. Uma das questões que mais importam para a redução das chances de aparecimento de degradação precoce em estruturas, é a contratação de um engenheiro tecnologista, disponível durante toda a execução da obra, sua assistência posterior, este profissional deve obedecer às normas, no geral, mas principalmente no que se refere à composição e confecção do concreto.

Verifica-se, dessa maneira, que um controle eficiente sobre a qualidade dos materiais a serem utilizados em uma construção passa a ser um dos fatores preponderantes para a redução da probabilidade de desgaste precoce em estruturas, e com isso a prevenir prejuízos futuros, tanto materiais quanto pessoais.

\section{MÉTODOS DE RECUPERAÇÃO ESTRUTURAL NO CONCRETO ARMADO}

Segundo Trindade (2015) a recuperação ou o reforço de estruturas de concreto são serviços dependentes de análise minuciosa dos fatores causais que os produziram, bem como da pesquisa, em detalhe, dos efeitos consequentes. A partir destas definições, o autor parte para a escolha do método mais eficaz, incluindo a seleção cuidadosa dos materiais e equipamentos a serem utilizados, e para a mão-de-obra para a execução do serviço.

Azevedo (2011) destaca que os serviços de reforço de estruturas avariadas requerem uma elaboração prévia de cálculo estrutural, não importando se o serviço deriva da necessidade de mudança da função principal da estrutura ou se é oriundo de um desgaste sofrido pela estrutura, em ambas as situações o reforço faz parte dos trabalhos de recuperação.

O cálculo permite estabelecer quais são os parâmetros necessários para a instauração de determinados fatores, tais como a definição exata das peças estruturais necessárias para proceder o reforço, bem como a extensão da intervenção, e para as outras estruturas onde apenas a recuperação será suficiente. Se faz mister destacar a reconstituição das características geométricas, de resistência e de desempenho originalmente programadas; a afirmação da capacidade de resistência residual da estrutura, ou peça estrutural, e, assim, a definição do tipo, severidade e dimensão do reforço que se faz necessário; a indicação da adoção, ou não, de serviços de escoramento durante a execução dos trabalhos; a análise do status de segurança da estrutura, no todo e em suas partes, prévia, durante e após o serviço de reforço; a seleção do método a ser utilizado; a definição das etapas necessárias e dos volumes reais de trabalho a ser realizado, ou seja, a definição do gasto real envolvido na empreitada, juntamente com os elementos da inspeção técnica efetuada (GONÇALVES, 2015).

O método de aplicação por meio de jatos d'água e de areia pode remover a camada degradada de concreto, a utilização de jatos d'água fria potável, frequentemente associada ao uso de jatos de areia, de forma alternada ou usando a mistura de ambos da mesma maneira que no concreto planejado por via seca. Quando da utilização do jato de areia se faz necessária a limpeza da mesma, a areia deve estar completamente seca e sem a presença de matéria orgânica, e esta deve ser descartada após o uso. A mangueira utilizada pode ser mantida, desde que a granulometria da areia esteja adequada ao calibre da mangueira, não permitindo entupimentos ou o polimento da superfície a ser recuperada (AZEVEDO, 2011).

Depois de finalizada a aplicação das soluções iniciais, são utilizados jatos de ar comprimido e de água fria, para que depois possam ser aplicados os materiais de recuperação (Figura 9). Esta técnica pode ser uma alternativa para o apicoamento do concreto, permitindo a retirada da camada mais superficial do concreto, embora seja cerca de 25 a $30 \%$ menos produtivo quando comparado à utilização apenas para a limpeza (SOUZA; RIPPER, 1998). 

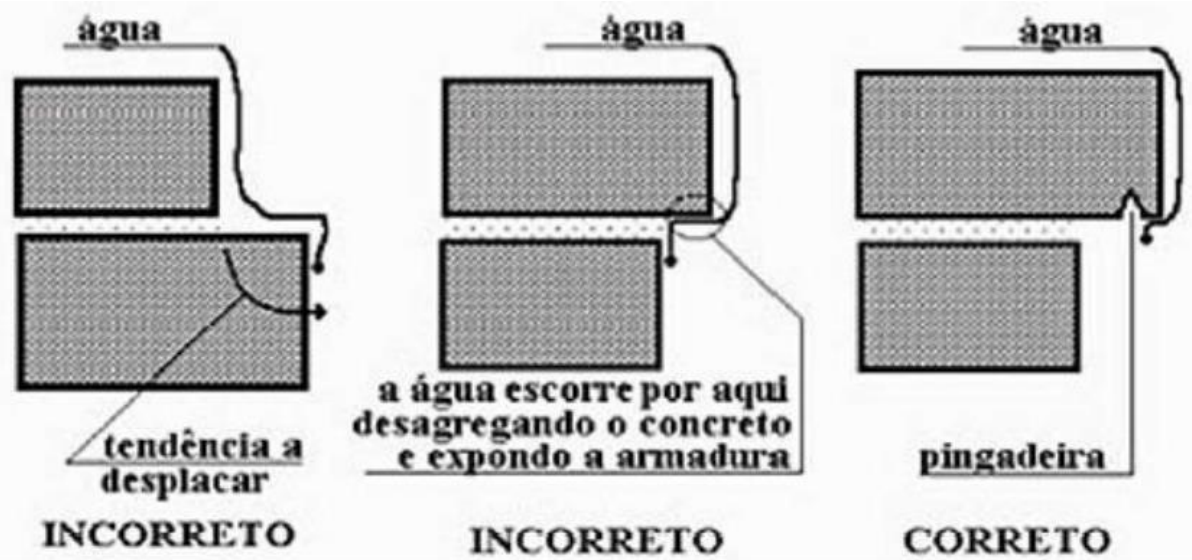

Figura 9 - Modelo estrutural com equívocos em relação ao ambiente. Fonte: Souza e Ripper (1998).

De acordo com Azevedo (2011), a utilização de jatos de água aquecida combinada a removedores biodegradáveis é uma opção para a remoção de resíduos muito gordurosos ou manchas bastante impregnadas em superfícies, porém a aplicação deverá ser realizada por operadores experientes, além da obrigatoriedade de utilização de EPI - Equipamento de Proteção Individual adequado. Frequentemente, utiliza-se um equipamento de alta pressão, do tipo lava-jato, caso seja possível, podem ser utilizadas algumas máquinas de projetar concreto de forma a reduzir o número de equipamentos alocados para a obra.

O jato de ar comprimido pode ser uma ferramenta complementar para a limpeza, nos casos onde os jatos de água ou areia não forem suficientes. A função do jato de ar comprimido é a de promover a retirada de partículas em cavidades, a direção do sopro deve ser do interior para o exterior, e deve-se proceder à secagem das superfícies ou de fissuras previamente à injeção das mesmas (SOUZA, 2006).

Gonçalves (2015) defende a utilização não como jato, mas como aspiração, essencialmente na limpeza de orifícios profundos, tais como aqueles presentes em ancoragem de barras de armaduras. Os principais cuidados de uso fazem referência ao uso de filtros de ar e óleo no equipamento compressor, a fim de evitar o refluxo de óleo.

Em determinados casos, o jato de limalha de aço pode ser uma possibilidade viável como substituta ao jato de areia. $\mathrm{O}$ equipamento tem seu funcionamento baseado nos mesmos princípios fundamentais de outros jatos, porém apresenta algumas características específicas. A limalha de aço é mais abrasiva que outros materiais e, por isso, é desaconselhável para utilização em armaduras expostas, com indícios de corrosão ou com diâmetros reduzidos. Nesse seguimento, o equipamento é menos poluente, quando comparado aos demais, além disso o método apresenta uma excelente eficiência para áreas extensas, sem a necessidade do uso de água. O jato pode quebrar a superfície de concreto menos resistente, além de permitir a abertura imediata dos poros, elevando a aderência do material de recuperação (SOUZA, 2006).

A técnica de queima à maçarico necessita de maior cuidado executivo, já que não é aconselhável a aplicação do maçarico em uma mesma área por um período de tempo maior, pois existe a possibilidade de dano no concreto saudável. Além disso, existe a restrição do uso em extensões com a armadura exposta, ou ainda em armaduras com um cobrimento inferior a $3,5 \mathrm{~cm}$. O método é eficaz para o tratamento de superfícies esfoliadas, para a remoção de substâncias gordurosas, como óleos e graxas. Devido ao exposto, e à possibilidade de execução inadequada, este método é muito pouco utilizado (TRINDADE, 2015).

Outra técnica, é a escovação manual, uma das técnicas de limpeza mais simples de serem utilizadas, conta com o auxílio de um equipamento acoplado a uma escova com cerdas de aço e, por vezes com o auxílio complementar de uma lixa de ferro (para uso em aço) ou d'água (para uso em concreto). O método é indicado para áreas pouco extensas, para a limpeza de barras com corrosão em estágios iniciais, e para aumentar a capacidade de aderência. Depois de 
terminada a escovação, deve-se proceder à limpeza da superfície tratada com jatos de ar comprimido (GONÇALVES, 2015).

O corte é a técnica usada para a remoção de partes de concreto degradado localizados a maiores profundidades. Esta técnica utiliza um martelo demolidor com massa entre seis e dez quilos, com o ponteiro terminando em ponta viva. Durante o processo retira-se completamente qualquer material danoso às armaduras, por meio de um corte de pelo menos dois centímetros ou do diâmetro da barra, com a profundidade ultrapassando as mesmas, o que garante que toda a armadura esteja imersa no meio alcalino. No caso de não haver o corte do concreto além das armaduras, onde a limpeza se dá apenas do lado externo e deixando a parte posterior ainda recoberta pelo concreto antigo, inicia-se uma pilha de corrosão eletroquímica pela diferença de material. Tal corrosão acontece pela parte posterior funcionar como um ânodo e pela parte restaurada como um cátodo, assim desencadeando um processo de corrosão mais veloz do que era originalmente (ANDRADE; PERDRIX, 1992).

Os prejuízos sofridos ao concreto são classificados em danos superficiais, danos semiprofundos ou profundos. Os primeiros são os danos com dimensões de até dois centímetros de profundidade, os danos semiprofundos são os com extensão de no máximo cinco centímetros de profundidade, e a partir deste valor os danos são considerados profundos (SOUZA; RIPPER, 1998). Por sua vez, Marcelli (2007) ressalta que os danos superficiais seriam aqueles com medidas de até $2,5 \mathrm{~cm}$ de profundidade.

Uma das características mais importantes para este tipo de argamassa de restauro é a alta resistência, a aderência adequada e, principalmente, a não retração desta, permitindo assim que todo o espaço vazio seja preenchido, obturando o problema de forma definitiva. Depois de finalizado o tratamento da superfície do concreto, a limpeza e os reparos nas ferragens, é possível proceder à restauração do elemento estrutural que a necessita (GONÇALVES, 2015).

O reparo com o uso do graute parece ser utilizado frequentemente quando é necessário desformar rapidamente o local que foi reparado, para a posterior utilização da estrutura. Como a alta resistência do graute é atingida muito rapidamente, as formas são retiradas em períodos de até 24 horas após executado (SOUZA; RIPPER, 1998). Este produto apresenta boa fluidez, compacidade, uniformidade, além de não ser retrátil, e ser auto adensável, com cura umedecida por um período de tempo de três dias (MARCELLI, 2007). Os grautes podem ser classificados como minerais, quando formulados a base de cimento ou como grautes poliméricos ou orgânicos, quando formulados à base de resina (SANABRIA; HELENE, 2000).

Segundo Relvas (2004), o reparo com a utilização de argamassa é um método utilizado em áreas menores, e de profundidades de no máximo cinco centímetros. Este procedimento é normalmente empregado somente em casos onde o que foi decomposto é a camada de concreto de cobrimento das armaduras. Assim, é de extrema relevância que a parte interna do elemento estrutural não mostre anormalidades, ou, no caso destas estarem presentes, que sejam sanadas anteriormente à utilização da técnica. Gonçalves (2015) também destaca que a argamassa pode ser útil na regularização de lajes, no preenchimento de pequenas falhas ou na reconstituição de quinas danificadas de elementos estruturais. Como para outras situações, todo o processo de recuperação deve ser precedido por uma limpeza completa da superfície a ser recuperada, estando livre de impurezas.

\section{METODOLOGIA}

A Revisão de literatura é um procedimento de investigação, apreciação e exposição de um corpo de informação que procura responder uma questão específica, ponderando sobre todo o material relevante, incluindo livros, artigos, registros, relatórios, teses, dissertações e demais categorias de obras publicadas (MARCONI; LAKATOS, 2018). Especificamente, quanto à revisão narrativa, essa não faz uso de parâmetros sistêmicos para buscar e analisar a literatura, e por vezes, a seleção das obras pode ser por conveniência, o que é uma forma de amostragem consolidada, e sujeita à subjetividade do autor. Como as demais revisões, a narrativa tem certas particularidades associadas aos 
objetivos pré-estabelecidos, recursos, dentre outros. Por se tratar do atual conhecimento científico, não é raro serem observados hiatos em alguns assuntos, e a revisão narrativa é exploratória, manifesta um caráter amplo, propondo-se à descrição e desenvolvimento de um tema, sob uma perspectiva teórica ou contextual, consoante a compreensão da produção científica. Tal sumarização a contar de tópicos abrangentes identifica as lacunas e subsidia a condução de novos estudos. Destarte, sua instrumentalização segue o rigorismo metodológico (LACERDA; COSTENARO, 2016).

A base metodológica da revisão bibliográfica narrativa foi apresentada por Elias, Silva, Martins, Ramos, Souza e Hipólito (2012) como uma metodologia que possibilita desenvolver artigos onde os autores analisam e ponderam de modo abrangente e crítico situações, fenômenos ou conceitos, sob uma perspectiva teórica. É fato que a escolha das fontes assegura uma análise mais aprofundada e legítima, na busca de informações acerca das especificidades do tema pesquisado. O estudo concebido com materiais já elaborados, especialmente livros e artigos científicos, tem grande poder exploratório, sendo desenvolvido de modo a trabalhar com conceitos teóricos, embora permita a ampliação do foco da pesquisa. A pesquisa bibliográfica é entendida como a fonte de toda a pesquisa, fundamentada em referenciais bibliográficos, isto é, dados obtidos de fontes escritas.

A revisão narrativa da literatura permite aprofundar a análise de forma a construir um estudo do tipo estado da arte, uma vez que permite constituir associações com obras publicadas anteriormente, assinalando tópicos recorrentes e apontando perspectivas inéditas, de forma a consolidar uma área de conhecimento. Com efeito, para que se possa executar um estudo qualitativo de revisão narrativa se faz imperioso analisar amplamente a literatura disponível, pelo estabelecimento de critérios, sem obedecer a uma metodologia extremamente rigorosa (VOSGERAU; ROMANOWSK, 2014). Porém, se faz essencial, para buscar e atualizar o conhecimento sobre o tema, evidenciar novas perspectivas, metodologias e subtemas encontrados na literatura mencionada (ELIAS et al., 2012).

A pesquisa exploratória pode envolver várias abordagens, como a qualitativa, usualmente baseada em hipóteses mais amplas, para CAUCHICK-MIGUEL (2018), os estudos exploratórios, comumente, são relevantes no diagnóstico de situações, na exploração de alternativas ou no desenho de novas ideias. Esses estudos são realizados mais amplamente, procurando estabelecer a natureza de uma questão e produzir mais dados que podem ser úteis à condução de novas pesquisas sobre o tema. Assim, mesmo nos casos onde o pesquisador já domina o assunto, o estudo exploratório ainda é relevante, uma vez que para um mesmo evento, haverá diversas explicações alternativas, e sua consideração irá permitir ao pesquisador a escolha da mais adequada. A disputa entre abordagens quantitativa e qualitativa é muito antiga, e baseia-se na forma pela qual os especialistas representam o real, se por meio de números ou por aspectos subjetivos, e em certas áreas a análise quantitativa não é capaz de compreender a magnitude do problema (FERREIRA, 2015).

A pesquisa qualitativa conforme Knechtel (2014) salienta a essência socialmente elaborada de uma realidade, relaciona o pesquisador e o objeto de estudo, enfatiza o modo pelo qual a experiência é adquire significado, faz uso de métodos interpretativos, aborda casos específicos, valora descrições pormenorizadas, e utiliza narrativas históricas. Na modalidade descritiva, a pesquisa abrange diversas informações com variáveis, as quais serão reduzidas e comporão a representação de uma dinâmica.

Assim, quanto à abordagem, o presente estudo é qualitativo; quanto à natureza á básico; quanto aos objetivos é exploratório-descritivo e quanto aos procedimentos é de pesquisa bibliográfica. A fim de responder à questão de pesquisa, foram acessados os websites de bibliotecas virtuais em bases de dados e realizada uma busca avançada, contemplando-se os termos delimitadores, especialmente nos últimos dez anos. As obras buscadas foram selecionadas e identificadas, os resumos lidos, e as obras completas selecionadas atenderam aos critérios estabelecidos para a inclusão: artigo de revisão ou original, ter sua versão completa disponível na base de dados, em idioma de língua portuguesa, espanhola ou inglesa, e, preferencialmente, publicada nos últimos dez anos, exceto para as obras consideradas clássicas. 


\section{CONSIDERAÇÕES FINAIS}

O presente trabalho permitiu uma análise acerca das patologias do concreto armado, isto é, por meio da realização de um levantamento completo das manifestações patológicas mais importantes no prejuízo de estruturas, foi capaz de apontar os principais sintomas, suas causas, mecanismos e consequências futuras destas nas edificações atingidas.

Conforme evidenciado no decorrer do trabalho, inúmeras são as causas e as origens responsáveis pelos problemas patológicos de uma estrutura, estas poderiam ser desencadeadas em diversas ocasiões, como nas fases de projeto, execução e utilização de qualquer um dos elementos envolvidos.

Dentre as diversas causas a serem arroladas, encontram-se as dificuldades da constituição química dos materiais escolhidos; os fenômenos naturais, como a sazonalidade; as falhas humanas de projeto e de execução, seja por negligência ou por qualidade insuficiente dos materiais elegidos, até mesmo a possibilidade de ataques biológicos e ação de agentes agressores às armaduras e ao próprio concreto.

O presente trabalho também enfatizou uma sequência de terapias capazes de recuperar e reforçar as estruturas de concreto armado que tenham sido acometidas por problemas patológicos. É notório que embora novas tecnologias estejam disponíveis para a recuperação de estruturas afetadas, todas elas trazem desvantagens e dificuldades que ainda não tem sua resolução satisfatória.

Cabe destacar, como conclusão desta pesquisa, que permanece a necessidade pela busca da qualidade para a construção civil, bem como em outros segmentos da engenharia civil. Se faz importante compreender que para uma estrutura de concreto armado atingir um bom nível de desempenho, sem a ocorrência de manifestações patológicas, a totalidade das esferas envolvidas deverá estar em perfeita sintonia, estas vão desde a mão-de-obra para a execução do projeto; seus projetistas; os materiais a serem utilizados; a compreensão e o entendimento do solo e do ambiente onde a obra será executada; enfim, todos os elementos deverão encontrar a harmonia de excelência. O fato de existir um excelente quadro de recursos humanos na área da execução não exclui ou reduz a necessidade de os materiais utilizados serem de alta qualidade e de procedência confiável. A fim de afastar a possibilidade de surgimento de problemas patológicos, todos os aspectos envolvidos devem estar em sintonia e apresentarem um padrão mínimo de aceitação, ou seja, nenhum deles deve estar em uma categoria demasiadamente inferior aos demais, sob pena de ocorrer uma falha em um setor, não compensada pela qualidade dos outros setores.

Os problemas que potencialmente atingem as estruturas são diversos e numerosos, e poderiam ser evitados pela adoção de cuidados mais rigorosos na confecção de projetos, na especificação e escolha dos materiais utilizados, no uso responsável da estrutura e de sua manutenção preventiva, tais cuidados poderiam, facilmente, reduzir, atenuar ou até extinguir a necessidade de sistemas de recuperação ou reparos de estruturas ameaçadas.

Com efeito, é possível verificar que a escolha adequada do método, a ser desenvolvido na recuperação estrutural, poderá garantir o sucesso da empreitada, e que uma escolha infeliz ou inadequada poderá ser capaz de instabilizar ou até colapsar o problema estrutural.

O diagnóstico, capaz de identificar e classificar a ocorrência ou a possibilidade de ocorrência de manifestações patológicas é uma das condições mais fundamentais a serem adotadas na conduta adequada frente a anomalias em edificações.

No entanto, é prudente questionar se a escolha e adoção de uma única técnica de inspeção e diagnóstico seria a mais indicada, já que para a construção de uma edificação se faz necessária a aplicação de diversos fatores, construtivos e executivos, bem como das diversas e dinâmicas circunstâncias inerentes à cada obra.

Embora sejam inegáveis as melhorias dos métodos e abordagens construtivas, o emprego da compatibilidade de projetos e a especialização da mão-de-obra, o surgimento das manifestações patológicas nas edificações poderão ser 
PATOLOGIA EM CONCRETO ARMADO E SEUS MÉTODOS DE RECUPERAÇÃO ESTRUTURAL

oriundos de diversos outros motivos, assim, cabe ressaltar que a implementação de programas eficientes de inspeção e manutenção constantes poderão assegurar e garantir a longevidade das edificações.

Assim, em síntese, o presente estudo analisou os principais métodos de recuperação estrutural em relação às patologias que ocorrem em concreto armado. Sugere-se, ainda, que outros estudos sejam desenvolvidos para discutir e fortalecer o tema da presente pesquisa, levando-se em consideração a evolução da sociedade e do mercado, bem como os principais autores da área de engenharia civil.

\section{REFERÊNCIAS}

ANDRADE Y PERDRIX, Maria Del Carmo. Manual para diagnóstico de obras deterioradas por corrosão de armaduras. Trad. Antonio Carmona, Paulo Roberto Lago. 5. ed. São Paulo, 1992.

AZEVEDO, Minos Trocoli de. Patologia das Estruturas de Concreto. v. 2. São Paulo: Ibracon, 2011.

BOTELHO, M. H. C.; MARCHETTI, O. Concreto armado eu te amo. São Paulo: Edgar Blucher, 2004.

BRASIL. Lei no 10.406 , de 10 de janeiro de 2002. Institui o Código Civil. Disponível em: http://www.planalto.gov.br/ccivil_03/LEIS/2002/L10406.htm. Acesso em: 17 nov. 2020.

CÁNOVAS, M. F. Patologia e Terapia do Concreto Armado. 1. ed. Trad. M. C. Marcondes; C. W. F. dos Santos; B. Cannabrava. 522 p. São Paulo: Pini, 1988.

CAUCHICK-MIGUEL, Paulo A. (Org.). Metodologia de Pesquisa em Engenharia de Produção e Gestão de Operações. 3. ed. Rio de Janeiro: Elsevier, 2018. ISBN: 978-85-352-9134-6. ISBN (versão digital): 978-85-3529135-3.

ELIAS, Claudia Souza Rodrigues; SILVA, Leandro Andrade; MARTINS, Miriam Teresa Sá Leitão; RAMOS, Neide Ana Pereira Ramos; SOUZA, Maria das Graças Gazel; HIPÓLITO, Rodrigo Leite. Quando chega o fim? Uma revisão narrativa sobre terminalidade do período escolar para alunos deficientes mentais. SMAD: Revista Electrónica em Salud Mental, Alcohol y Drogas, São Paulo, v. 8, n. 1, p. 48-53, 2012. ISSN: 1806-6976.

FERREIRA, Carlos Augusto Lima. Pesquisa quantitativa e qualitativa: perspectivas para o campo da educação. Revista Mosaico, Vassouras-RJ, v. 8, n. 2, p. 173-182, jul./dez. 2015. ISSN: 2178-7719.

FIGUEROLA, Valentina. Vazios de Concretagem. n. 109, abr. 2006. São Paulo: Revista Techne, 2006.

GONÇALVES, Eduardo Albuquerque Buys. Estudo de Patologias e suas Causas nas Estruturas de Concreto Armado de Obras de Edificações. 2015. 174 f. Monografia (Graduação em Engenharia Civil). UFRJ - Universidade Federal do Rio de Janeiro. Escola Politécnica. Rio de Janeiro: UFRJ, 2015.

HELENE, Paulo R. L. Manual prático para reparo e reforço de estruturas de concreto. 119 p. São Paulo: Pini, 1992.

HERANI, Thais da Silva Ambrósio Garcia. Patologia, tratamento e reforço de estruturas de concreto no metrô de São Paulo. 2004. 73 f. Monografia (Pós-Graduação Latu Senso em Construções Civis: Excelência Construtiva e Anomalias). Universidade Presbiteriana Mackenzie. Escola de Engenharia. São Paulo: Universidade Presbiteriana Mackenzie, 2004. Disponível em: https://pt.scribd.com/document/377502295/Thais-Da-Silva-Ambrosio-GarciaHerani1. Acesso em: 17 nov. 2020

ISAIA, Geraldo C. Controle de Qualidade das Estruturas de Concreto Armado. 119 p. Santa Maria: Edições UFSM, 1988.

KNECHTEL, Maria do Rosário. Metodologia da pesquisa em educação: uma abordagem teórico-prática dialogada. Curitiba: Intersaberes, 2014.

LACERDA, Maria Ribeiro; COSTENARO, Regina Gema Santini. (Orgs). Metodologias da pesquisa para Enfermagem e Saúde: da teoria à prática. 1. ed. Porto Alegre: Moriá, 2016. 496 p. ISBN: 978-85-99238-17-2.

MARCELLI, M. Sinistros na construção civil: causas e soluções para danos e prejuízos em obras. São Paulo: Pini, 2007.

MARCONI, Marina De Andrade; LAKATOS, Eva Maria. Metodologia Cientifica. São Paulo: Atlas, 2018. 390 p. ISBN-10: 8597011831. ISBN-13: 978-8597011838. 
MIOTTO, Daniela. Estudo de Caso de Patologias Observadas em Edificação Escolar Estadual no Município de Pato Branco-PR. 2010. 63 f. Monografia (Pós-Graduação em Construção de Obras Públicas). UFPR - Universidade Federal do Paraná. Programa de Residência Técnica da Secretaria de Estado de Obras Públicas (SEOP). Curitiba: UFPR, 2010. Disponível em:

https://acervodigital.ufpr.br/bitstream/handle/1884/34353/MIOTTO,\%20DANIELA.pdf. Acesso em: 17 nov. 2020.

NEVILLE, A. M.; BROOKS, J. J. Tecnologia do Concreto. 2. ed. ISBN: 9788582600719. Bookman, 2013.

RELVAS, Fernando José. Curso de estruturas de concreto: projeto, execução e reparo. Reforço de peças de concreto armado, com chapas de aço. dez. 2004.

SANABRIA, Leonel Tula, HELENE, Paulo R. L. Contribuição ao estudo da resistência à corrosão de armaduras de aço inoxidável. Tese (Doutorado em Engenharia Civil). USP - Universidade de São Paulo. São Paulo: USP, 2000.

SOUZA, Erick Almeida da. Técnicas de recuperação e reforço de estruturas de concreto armado. $2006.84 \mathrm{f}$. Monografia (Graduação em Engenharia Civil). Universidade Anhembi Morumbi. São Paulo: Universidade Anhembi Morumbi, 2006

SOUZA, V. C.; RIPPER, T. Patologia, recuperação e reforço de estruturas de concreto. 255 p. São Paulo: Pini, 1998.

TAKATA L. T. Aspectos executivos e a qualidade de estruturas em concreto armado: Estudo de caso. 2009. Dissertação (Mestrado em Engenharia Civil). UFSCar - Universidade Federal de São Carlos. São Carlos: UFSCar, 2009.

THOMAZ, E. Trincas em Edifícios: causas, prevenção e recuperação. São Paulo: Pini, 1989.

TRINDADE, Diego dos Santos da. Patologia em Estruturas de Concreto Armado. 2015. 88 f. Monografia (Graduação em Engenharia Civil). UFSM - Universidade Federal de Santa Maria. Centro De Tecnologia. Santa Maria: UFSM, 2015

VOSGERAU, Dilmeire Sant'Anna Ramos; ROMANOWSKI, Joana Paula. Estudos de revisão: implicações conceituais e metodológicas. Revista de Diálogo Educacional, Curitiba-PR, v. 14, n. 41, p. 165-189, 2014. ISSN: 1981-416X.

Informações sobre os autores:

JJAJ: Doutor em Sistema de Produção - UNESP - Ilha Solteira - SP. Endereço para contato Rua R004 Qd. 7 Lt. 11 - Vila Verde - Rio Verde - GO. CEP 75.909-130. E-mail: E-mail: joaquimjuliojr@gmail.com

TSF: Engenharia Civil - Centro Universitário de Mineiros - UNIFIMES

BCM: Engenharia Florestal - Centro Universitário de Mineiros - UNIFIMES

VJAS: Acadêmico de Direito - Faculdade Almeida Rodrigues - FAR

Contribuições dos autores: (JJAJ, TSF, BCM, VJAS) conceitualização, captação de recursos, supervisão, redação 